Volume 5, Issue 2, June 2020, pp. 175 - 186

DOI: $10.23917 /$ jramathedu.v5i2.10286

p-ISSN: 2503-3697, e-ISSN: 2541-2590

\title{
Students' visual thinking ability in solving the integral problem
}

\author{
Ummu Sholihah*, Maryono Maryono \\ Tadris Matematika, Institut Agama Islam Negeri Tulungagung, Indonesia \\ Corresponding author: u.sholihah@yahoo.com
}

\begin{tabular}{l} 
ARTICLE INFO \\
\hline Article history: \\
Received: 18 February 2020 \\
Revised: 21 May 2020 \\
Accepted: 25 May 2020 \\
Published online: 27 June \\
2020 \\
Published regularly: June \\
2020
\end{tabular}

Keywords:

Visualization, visual thinking, definite integral.

\begin{abstract}
Visual thinking plays an essential role in solving problems and in learning mathematics. Many students do not understand how to graphically or geometrically represent problems and solve algebra problems. Visual thinking is the ability, process, and results of creating, interpreting, using, and imagining images and diagrams on paper or with technological tools, describing and communicating information and ideas, developing ideas, and understanding improvement. This research describes students' visual thinking ability to solve integral problems. The approach used in this study was descriptive qualitative. The subjects in this study were three students from the Department of Mathematics Education at the State Islamic Institute of Tulungagung. The data were collected by using tests and interviews. The steps to analyze the data were categorization, reduction, exposure, interpretation, and conclusion. Based on the analysis of students' visual thinking skills in solving integral problems, there were three levels of visual thinking: semi-local visual, local visual, and global visual. At the semi-local visual level, students could only understand algebraically, and they have not shown it graphically at all. Meanwhile, at the local visual level, they have already understood geometry as an alternative language and been able graphically represented problems or concepts, even though it was not perfectly done yet. While on a global visual level, they could perfectly visualize visual thinking indicators, understand algebra and geometry as alternative languages for problem-solving, extract specific information from diagrams, graph problems, and use them to solve problems perfectly.
\end{abstract}

\section{Introduction}

Mathematics learning in higher education plays a crucial role in the development of thinking ability, problem-solving, and student independence. Mathematics learning in higher education needs to be highlighted, in terms of understanding concepts correctly and adequately, the mathematics of reasoning skills in techniques and methods in mathematics, and the ability to learn independently. Understanding a mathematical concept is resulted from constructing or reconstructing mathematical objects. The construction or reconstruction takes place through activities in the form of mathematical actions, processes, and objects organized in a scheme for solving a problem (Dubinsky, 2013). The curriculum has great significance for teachers in any education system, as it often serves a

To cite this article:

Sholihah, U., \& Maryono, M. (2020). Students' visual thinking ability in solving the integral problem. JRAMathEdu (Journal of Research and Advances in Mathematics Education), 5(2), 175-186. doi:https://doi.org/10.23917/jramathedu.v5i2.10286 
book for teachers. Many teachers are still afraid of being creative in teaching activities and not moving out of the prescribed curricula. The curriculum is still a subject to be completed in each academic session (Umami, 2018). Some results of the studies showed that smart students seem to prioritize the use of symbols and visualization that are not useful (Tasman et al., 2016).

Visualization is an interesting area for researchers involved in mathematics education. Visualization is a fundamental aspect of students' understanding of mathematical concepts (Arcavi, 2003; Stylianou, 2004). Their views on visualization suggest that visual thinking can be an alternative. Students' ability to work on mathematics, and possibilities that make thinking about mathematics besides language and logicalproportional thinking, are more traditional and contain traditional algebraic symbols. The ability of visual thinking plays an important role, including the ability to make it easier to understand complex problems, to simplify problems, to identify relationships with related problems, rather than to perform calculations. Suharnan (2005) argues that students at the formal level, where they can name a concept or acceptable attributes, can correctly give examples of objects with these attributes and can indicate the reasons underlying the definition, and can connect between representations to solve the problem.

Representation is as any sign, object, and character that stands for something other than itself, and that is used to describe, depict, symbolize, encode, and/or represent mathematical concepts and processes (Goldin, G., \& Shteingold, 2001). The roles of representation in mathematics learning are that: 1) representation helps students in making sense of mathematics tasks and concepts; 2) representation facilitates students' learning process; 3) representation helps students in managing and expressing their thinking as well as making a mental model of their mathematical ideas; 4) representation helps students understanding abstract mathematical concepts; and 5) being used to mathematics problems with multiple representations helps students in analyzing problems (Kang, R., \& Liu, D, 2018). Suh et al. (2008) also explain that the students' representations can be a tool for teachers to interpret the students' responses to a task in the classroom. The learning method triggers students to work (learning by doing) based on daily problems or contextual problems (Nufus, Duskri, \& Kuala, 2018)

Visual thinking is the ability, process, and results of creating, interpreting, using, and imagining images and diagrams on paper or with technological tools, describing and communicating information and ideas, developing ideas, and understanding improvement. (Arcavi, 2003). Visual thinking is also defined by Kurniawati (2013) as the ability to visualize, transform, generalize, communicate, document, and reflect on objects. Stokes (2001) describes visual thinking as the ability to transform information from many images, graphics, or other forms that help to communicate information. Some studies highlighted how important visual thinking (Güven \& Kosa, 2008; Huang, 2013; Suharnan, 2005), explaining that visual thinking could enhance memory and creative thinking skills in learning mathematics, including calculus.

Calculus offers mathematics courses at the undergraduate. Two problems in calculus are derivatives and integral. The integral of a function can be geometrically interpreted as the area under the curve of the mathematical function $\mathrm{f}(\mathrm{x})$ plotted as a function of $\mathrm{x}$. However, many students have difficulty in understanding the concepts of integral calculus (Mahir, 2009). It is for the desire of students who focus on integration practices by not strengthening the understanding of the integral concept. Umami (2018) affirms that educators should be patient in explaining integral procedures without understanding wonderful concepts. 
In learning the Integral concept, students need to understand the number of areas, boundaries, areas, and other concepts (Serhan, 2016). To understand integral concepts, students must be able to relate previously related concepts to build their recent knowledge. The Calculus textbook introduces integral as inverse-derivatives because integrals are known as anti-derivative functions. When learning integrals, one must first understand the concepts of limit and derivative. Therefore, educators must introduce derivation before going into the integral.

In calculus, integrals are represented numerically, algebraically, graphically, and verbally, so students understand the relationship between representations and develop understanding concepts. One of them is by developing visual thinking skills. There are several indicators of visual thinking: 1) to understand algebra and geometry as alternative languages; 2) to extract specific information from diagrams; 3 ) to represent and interpret problem (or concept) graphically; 4) to draw and use diagrams as an aid in problemsolving; and 5) to understand mathematical transformations visually (Huang, 2013). The level of visual thinking corresponds to the depth of information processing. According to Sternberg (2008), there is no boundary between one level of information processing and the next level. The level of student visual thinking is different for each person, activity, and task. As Huang (2013) argues, there are three levels of students' visual thinking abilities, namely non-visual (NV), local-visual (LV), and global-visual (GV), with the characteristic shown in Table 1.

Table 1

Visual thinking of three levels

\begin{tabular}{lccc}
\hline \multicolumn{1}{c}{ Visual thinking abilities } & $\mathrm{NV}$ & $\mathrm{LV}$ & $\mathrm{GV}$ \\
\hline to understand algebra and geometry as alternative languages & $\times$ & $\circ$ & 0 \\
to extract specific information from diagrams & $\times$ & $\circ$ & $\circ$ \\
to represent and interpret problem (or concept) graphically & $\times$ & $\Delta$ & 0 \\
to draw and use diagrams as an aid in problem-solving & $\times$ & $\Delta$ & 0 \\
to understand mathematical transformations visually & $\times$ & $\circ$ & 0 \\
\hline
\end{tabular}

${ }^{x}$ denotes that students have not demonstrated the competency in the problem solving

$\Delta$ denotes that students have not demonstrated the competency fully in the problem solving

$\circ$ denotes that students demonstrated the competency completely in the problem solving

Subsequently, based on the characteristics of the existing levels, the researchers performed observations to find out the visual thinking skills of students of the Mathematics Education at the State Islamic Institute of Tulungagung, Indonesia. Based on the observation, the features of the students' visual thinking are: (1) in solving problems, students planned their thoughts to understand the problems. For example, the students said that after reading the problem; the brain presented itself in its knowledge; (2) students could edit the area using a graphical representation; (3) students could work graphically and algebraically, but could not establish relationships; (4) students could graphically represent and interpret problems; (5) prioritizing analytical thinking rather than visual thinking; (6) understanding the relationship between integrals and area.

The observation also showed that some students did not satisfy the existing level of indicators for visual thinking skills (Huang); students have demonstrated the competency in the problem solving algebraically and geometrically, but not completely for all problems. It is known that there was a positive relationship between visual thinking and problem solving (Guler \& Ciltas, 2011; Huang, 2013). Therefore, the description of students' visual thinking skills in more detail is needed, especially when solving problem areas of the integrals with multiple representations. Hence, the main contribution of this research is 
provides an insight to improve the integral learning process, especially in solving integral problems using various representations.

\section{Research Methods}

The approach used in this study was qualitative descriptive. The subjects selected were six students of 35 students from the Department of Mathematics Education at the State Islamic Institute of Tulungagung in the Academic Year of 2017/2018. The sampling technique used was purposive sampling. The data were collected by using tests and interviews. The test was used to determine students' ability to think visually in solving integral problems. The test comprised two integral problems. Besides, each interview lasted about 40-50 minutes and was video-recorded and audio-taped.

The steps of analyzing data included reduction, presentation, and conclusions. All activities were carried out in parallel during the process of collecting the data. The data reduction activities on interview results were performed. Firstly, summarizing the interview results in the form of note-taking the information from the students was done. Secondly, sorting out the data between the most and least important based on indicators had determined was carried out. Finally, the most important data were analyzed. The interview's main role was to reveal information about the ability of visual thinking in solving the integral problem deeply. The data were presented in a descriptive based on the reduction activities. It made it easier to understand what happened in the systematic organization of the data. The conclusion drawing by the researcher should be supported by valid data. In this phase, the conclusion would be based on the results of the analysis of the whole data, and the test instrument of this study comprised of two problems, which are shown below.

1. Using algebra and geometry to calculate $\int_{-5}^{5}|x+3| d x$.

2. Drawing the area $R$ bounded by $y=x+6, y=x^{3}$ and $2 y+x=0$. Then, the area of $R$ was calculated. (Instructions: divide $\mathrm{R}$ into 2 )

\section{Results and Discussion}

\section{Case 1. Student's visual thinking ability of the semi-local visual level}

The semi-local visual subject (SLV) could only understand algebraically when solving comprehensive problems with integrals. The subject did not show the ability to solve problems fully as shown in Figure 1.

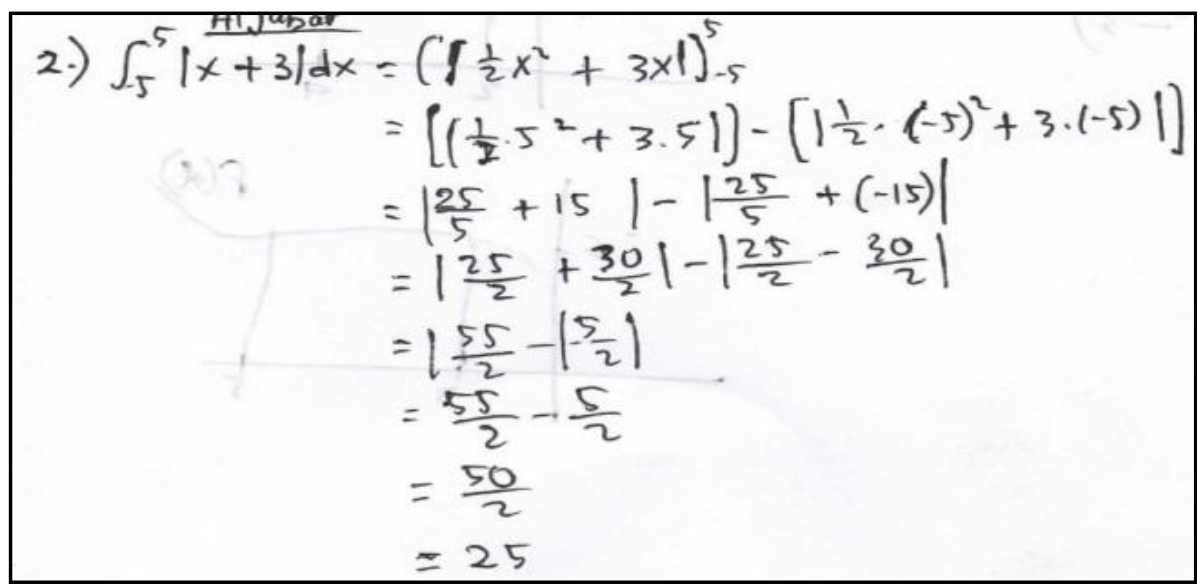

Figure 1. Algebraic answer for task 1 of the student with semi-local visual level 
In Figure 1, the subject wrote $\int_{-5}^{5}|x+3| d x=\left|\frac{1}{2} \cdot x^{2}+3 x\right|_{-5}^{5} d x$ directly if $d x$ was crossed. Then, he replaced the upper and lower bounds by $\left|\frac{1}{2} \cdot(5)^{2}+3.5\right|-\mid \frac{1}{2} \cdot(-5)^{2}+$ $3 .(-5) \mid$. Even though it is procedurally correct, however, the conceptually is incorrect as well as the solution. The subject drew only one line number with the value of the integral limit of -5 and 5 . After that, he joined both value although without meaning. The subject showed difficulty in solving integral problems both algebraically and geometrically. He did not really understand the concept of absolute value and referred to the integral concept of problem-solving. He could graph the function but did not understand the meaning. The subject could not represent problems or concepts graphically as shown in Figure 2.

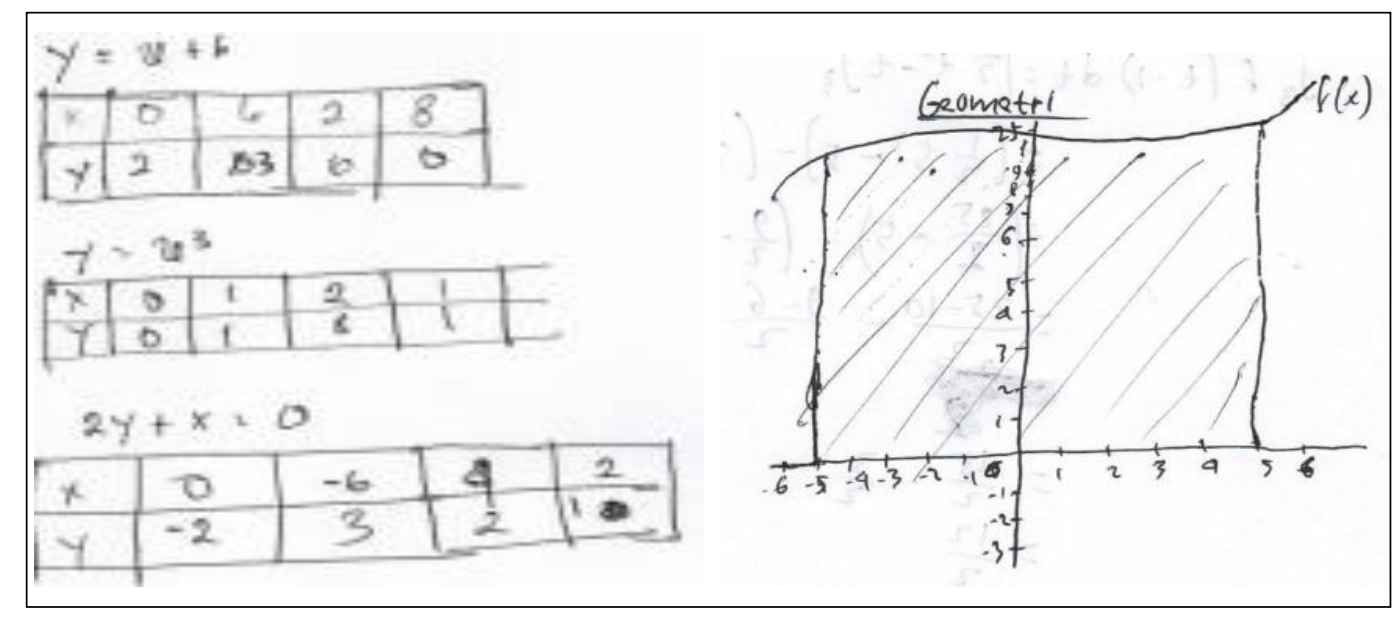

Figure 2. Algebraic answer for task 1 of the student with semi-local visual level

In solving Problem 2, the subject wrote the function in table. For the equation, $y=x+6$, if $x=\{0,6,2,8\}$, then $y=\{2,12,0,0\}$. For the equation, $y=x^{3}$, obtained $x=\{0,1,2,1\}$ by assuming $y=\{0,1,8,1\}$. Then, for the equation, $2 y+x=0$, if $x=$ $\{0,-6,4,2\}$ then $y=\{-2,3,2,0\}$. Some answers were incorrect. It can be considered that the subject was difficult to understand algebra and geometry as alternative languages. He could not draw and use diagrams as an aid in solving problems properly. He asked a diagram problem from a particular function which he did not know. It is consistent with the excerpt of the interview as follows ( $R=$ researcher).

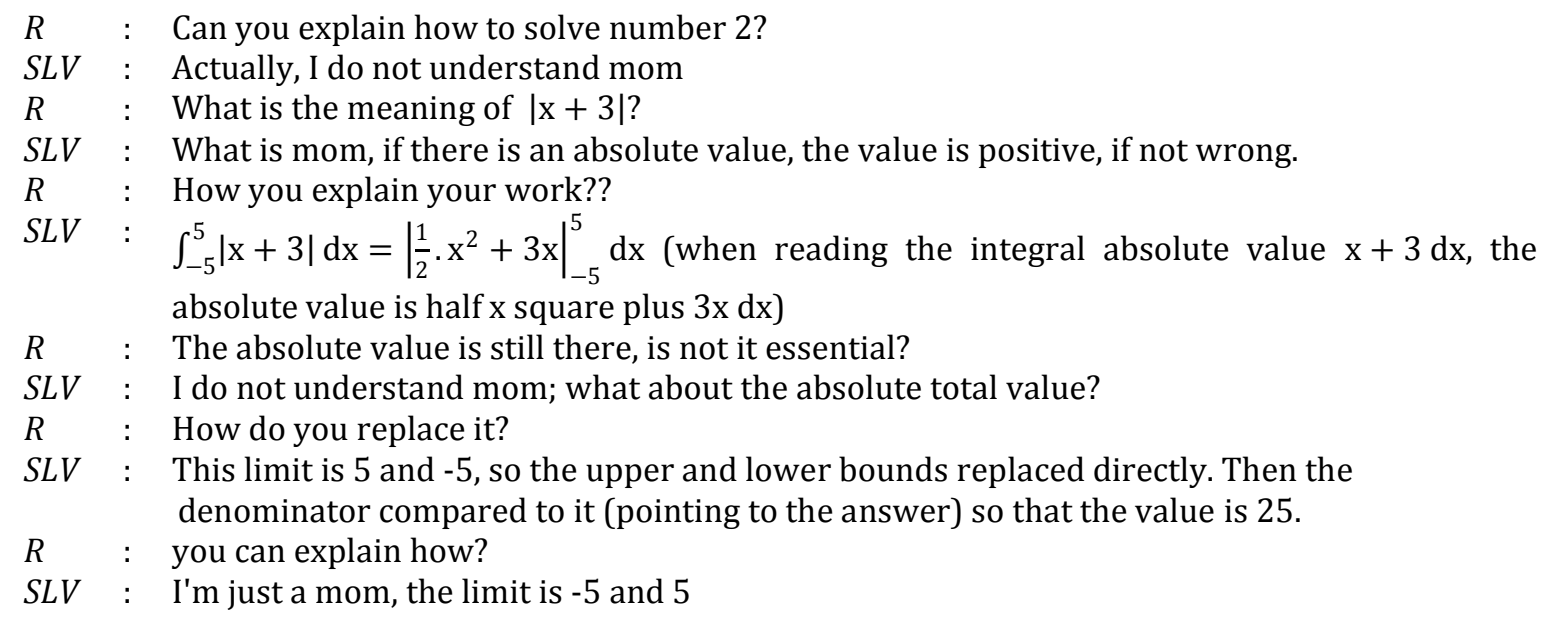


Based on tests and interviews, the subject could understand the relationship between area and integral. He could use the symbolic representation even though incomplete. He still lacked the concept and unable to describe each provided function when he was drawing. It can be considered that the subject performed the instrumental understanding. This understanding is refer to the use of methods or rules without knowing the reason (Skemp, 2013). The subject could solve the problem even though incomplete. This problem is consistent with the earlier understanding and simple recognition of the image of the topic studied (Suharnan, 2005). Suharnan stated that to find a correct solution, the subject should understand and recognize the material.

The subject could develop visual methods to understand concepts and problems. However, he could not determine the area based on the overall picture. In graphing and interpreting the problem (the concept), the subject could not manipulate the area using graphical representations correctly or incomplete. He was unable to draw the diagrams. It showed that the subject has not understood the methods to transform the problem into the images. Presmeg (2006) stated that visualization can solve mathematical problems, especially mental images of subjects controlling student thinking. At this level, the standard mental image has dominated in thinking while drawing graphics to solve problems. Based on Huang's (2013) level of thinking, the subject did not met completely the existing indicators; non-visual and the local visual level indicators. We called this characteristic by a semi-local visual level (SLV). The apparent differences in the theme of solving problems or explaining their method of thinking are supported by Van de Walle (2008). He stated that no one think geometry ideas in the same way because everyone can grow and develop their ability to think in geometry.

\section{Case 2. Student's visual thinking ability of the local visual level}

The local visual subject (LV) showed the ability to solve problems even though the graph was incomplete. The subject understood algebra and geometry when solving problems. However, she did not demonstrate his ability completely as shown in Figure 3 below.

$$
\begin{aligned}
& \int_{-5}^{5}|x+3| d x=\left[\left|\frac{1}{2} x^{2}+3 x\right|\right]_{-5}^{5} \\
& \Rightarrow \int_{-5}^{5}|x+3| d x=\left[\left|\frac{1}{2} x^{2}+3 x\right|\right]_{-5}^{5} \\
&=\left[\left|\frac{1}{2}(5)^{2}+3(5)\right|\right]-\left[\left|\frac{1}{2}(-5)^{2}+3(-5)\right|\right] \\
&=\left[\left|\frac{25}{2}+15\right|\right]-\left[\left|\frac{25}{2}-15\right|\right] \\
&=\left|\frac{25+30}{2}\right|-\left|\frac{25-30}{2}\right| \\
&=\left|\frac{55}{2}\right|-\left|\frac{-5}{2}\right|=\frac{55}{2}-\frac{5}{2}=\frac{50}{2}=25 \text { satuan luas }
\end{aligned}
$$

Figure 3. Algebraic answer for task 1 of the student with local visual level

Figure 3 shows that the subject solved the problem directly by writing the integral $\int_{-5}^{5}|x+3| d x=\left|\frac{1}{2} \cdot x^{2}+3 x\right|_{-5}^{5}$. Then, she replaced the upper and lower limits, leaving the absolute value to the result. Hence, even though she could answer the integral problem, 
however, it is incomplete. The procedure is correct, however, the concept is incorrect. She could represent problems both graphically and algebraically even though incomplete. The subject understood the concept of absolute value, however, it was incomplete. It is consistent with the excerpt of the interview.

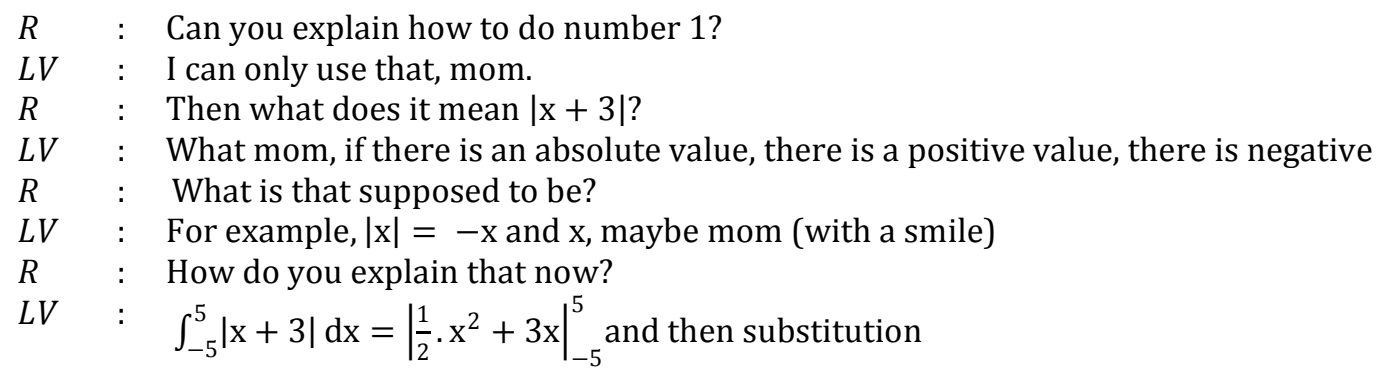

In solving Problem 2, the subject wrote a function in table $x=\{-6,-4,-2,0,2\}$ for the equation, $y=x+6$ to obtain $y=\{0,2,4,6,8\}$. For the equation $y=x^{3}$, where $x=\{0,1,2,-1,-2\}$ then $y=\{0,1,8,-1-8$,$\} . Finally, for the equation, 2 y+x=0$, because of $x=\{0,2,4,-2,-4\}$ then $y=\{0,-1,-2,1,2\}$. The answer of the subject of task 1 is shown in Figure 4.

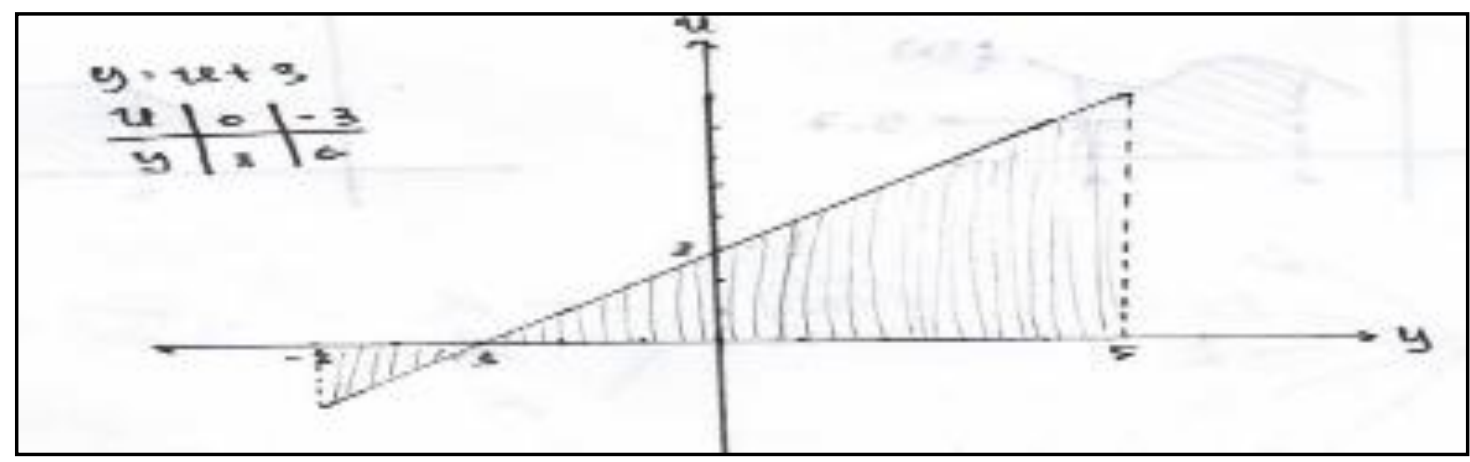

Figure 4. Graphic answer for task 1 of the student with local visual level

The subject could understand the relationship between range and integrals, but incomplete. She could use symbolic representation even though incomplete. The understanding of concepts of the subject is only recalling the material from a high school. She could describe any function, however, it was incomplete. This characteristic is confirmed by Suharnan (2005) and Sternberg (2008) which stated that recognizing patterns is the first process to recognize a received stimulus. Once a pattern has been identified, the pattern must be processed or organized.

The subject could also develop a visual method to find the concepts and problems. She could measure the surface by determining the overall image. However, the solution was incomplete. It can be seen that the next activity after knowing is the visualization. Roam ( $\underline{2011}$ ) and Suharnan ( $\underline{2005}$ ) stated that this notion, visualization, is the stage of processing visual inputs to bring back objects or events. In other words, students can develop their ability to think in different geometric contexts to solve the integral problems.

Representations could be handled or resolved with graphics. The subject ability to draw a topic chart was clear, however, it was still incomplete. She could not transform the problem into images using a visual image or imagination that integrated into the image experience with the theme of past and present problems. However, she could develop visual methods to understand concepts and problems. The repetition of scanning 
information to achieve the correct visual input may occur in imaginary activities (Sholihah \& Asyhar, 2018) and should repeat purposely.

\section{Case 3. Student's visual thinking ability of the global visual level}

The global visual subject $(\mathbf{G V})$ fulfilled the indicator of the creative thinking completely. She could represent and drew problems or concepts in algebra and geometry. The subject used his understanding of the concepts to solve problems as presented in Figure 5.

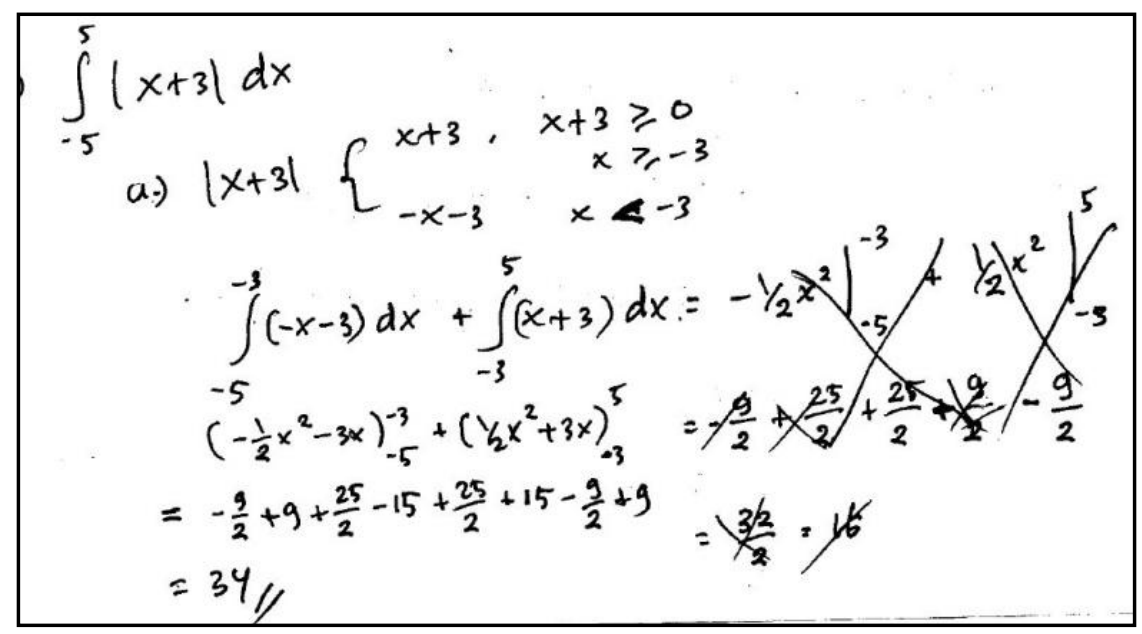

Figure 5. Algebraic answer for task 1 of the student with global visual level

Figure 5 showed that the subject could solve the problem of the integral of the absolute value algebraically. The solution steps were systematically and correct. The subject understood the relationship between the domain and the integral. She also understood the concept of the absolute value function well. The subject represented the value of the function as shown in Figure 6.

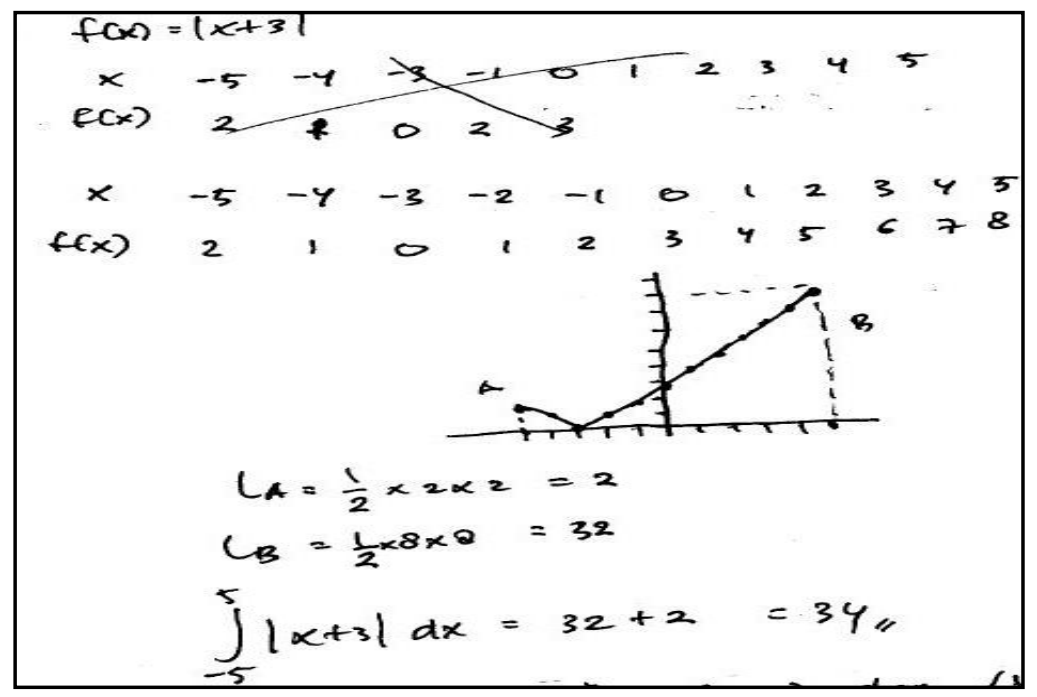

Figure 6. Graphic answer for task 1 of the student with a global visual level

In Figure 6, the subject first created the coordinate points $\mathrm{x}$ and $\mathrm{y}$, then created the graph. Furthermore, she divided the area into two, A and B, which represent the two 
triangles. The subject then calculates the area of the triangle using the formula. The results were $A=2$ and $B=32$. It can be seen that the subject has the ability to develop visual methods to see concepts and problems better. The excerpt of the interview is consistent with the analysis.

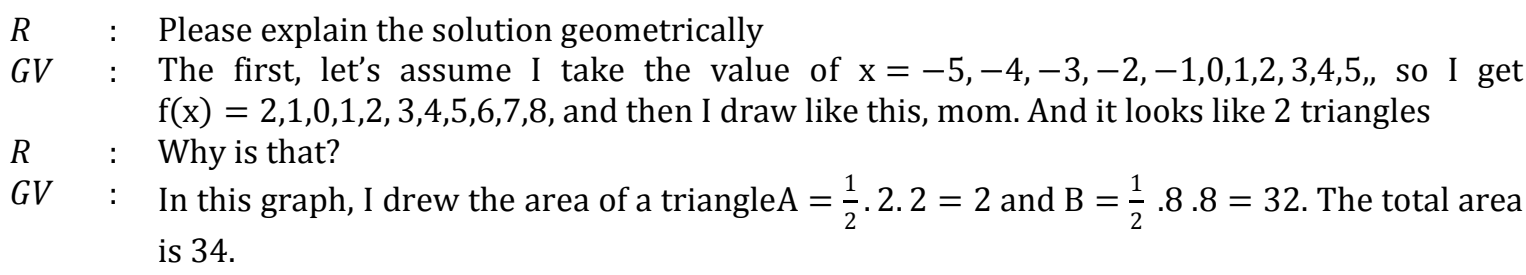

In Task 2, firstly, the subject found the intersection each equation. Then, she plotted the graph to determine the area as shown in Figure 7.

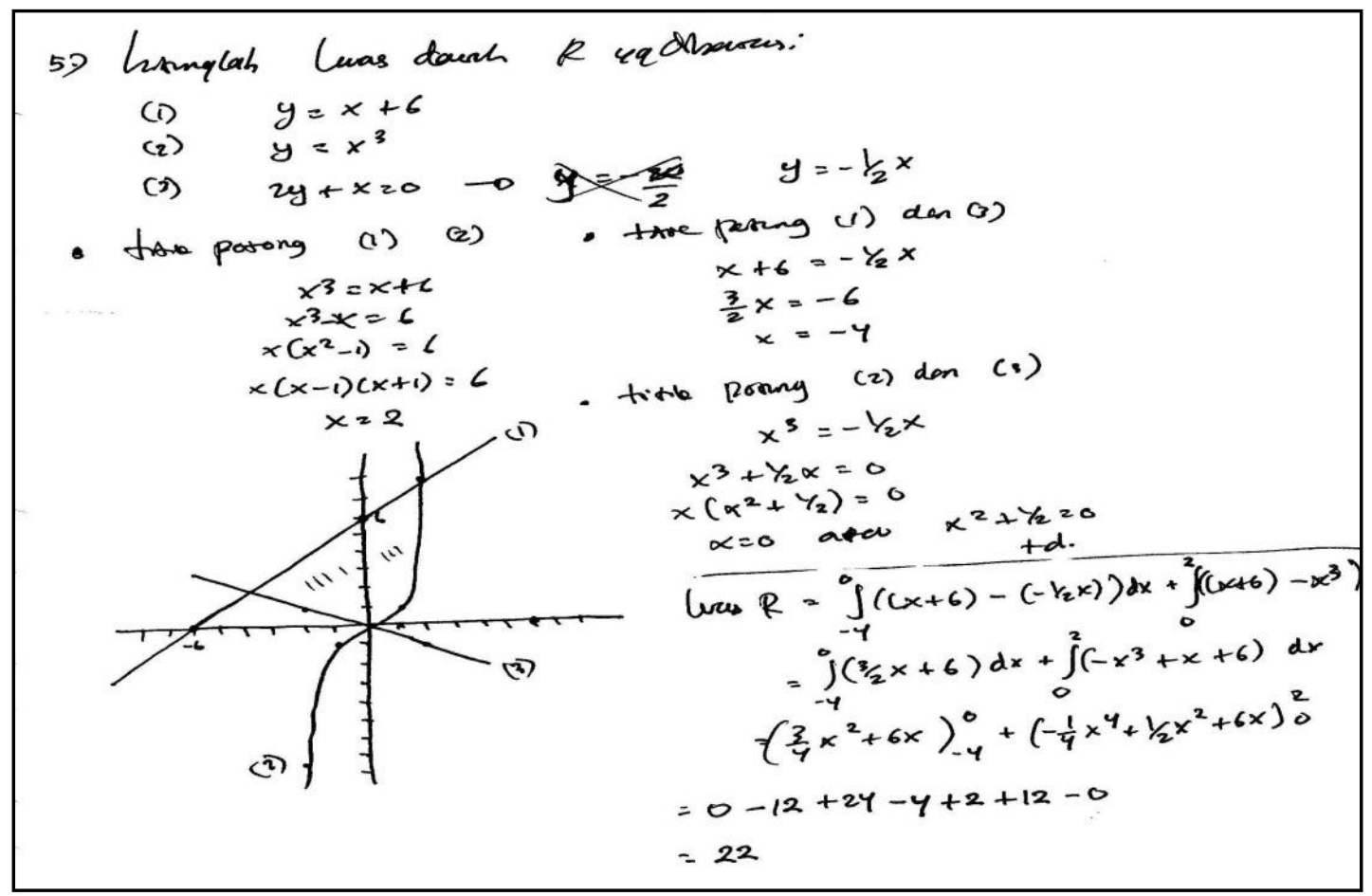

Figure 7. Algebraic and graphic answer for task 2 of the student with global visual level

Figure 7 showed that the boundary of the area is $0,2,-4$, and 0 . The next step was completed the task by integrating the two areas. The solution showed that the subject could represent the problem algebraically and geometrically. She was also performed well on the procedurally. It means that the subject could manipulate and calculate all the steps to solve the problem correctly. The subject also manipulates the area using graphical representations according to the changes in integral symbols correctly. The subject understood the concept of integrals very well. It is consistent with the results of the following interview.

$R \quad: \quad$ Explain the steps for solving the problem

$G V$ : The first I find the intersection of each equation; (1) and (2); $\mathrm{x}^{3}=\mathrm{x}+6 ; \mathrm{x}^{3}-\mathrm{x}=$ $6 ; x\left(x^{2}-1\right)=6 ; x(x-1)(x+1)=6 ; x=2 ;$ then (1) and (3) $x+6=-\frac{1}{2} x ; \frac{3}{2} x=-6 ; x=$ -4 ; the last (2) and (3) 
The topic has met all indicators of visual thinking. The subject could understand the relationship between area and integral and could use the symbolic representation. The subject could also describe any function completely. The students in this group were different from those at the local-visual level in that they had to understand algebra and geometry as alternative languages, represented and interpreted problems (or concept) graphically, drew, used diagrams as an aid in problem-solving, and understood mathematical transformations visually. This stimulus or activity input showed that an image of the definition is a suitable visual input explanation. The information processing proceeds from the input stimulus (Schunk Dale H., 2012). The subject explained the relationship between the geometry, although it was not yet possible on a formal level based on the information provided. The subject could solve the specified problem. The subject could also develop visual methods to understand concepts and problems better. According to Roam (2011) and Suharnan (2005), this notion is the stage of processing visual inputs to bring back objects or events since everyone can grow and develop their ability to think in different geometric contexts. Scanning to get information was carried out, as in the opinion of Sternberg ( $\underline{2008}$ ) that drawing people's attention is to scan information from active memory. According to the data analysis, competencies of visual thinking in solving the integral problem of each level are shown in Table 2.

Table 2

Competencies of the three levels of visual thinking

\begin{tabular}{|c|c|c|c|}
\hline Visual thinking abilities & SLV & $\mathbf{L V}$ & GV \\
\hline to understand algebra and geometry as alternative languages & $\Delta$ & O & O \\
\hline to extract specific information from diagrams & $\Delta$ & O & O \\
\hline to represent and interpret problem (or concept) graphically & $x$ & $\Delta$ & ○ \\
\hline to draw and use diagrams as an aid in problem-solving & $\times$ & $\Delta$ & ○ \\
\hline to understand mathematical transformations visually & $\times$ & o & ○ \\
\hline
\end{tabular}

In Table 2, it shows that the subject of the global visual level (GV) demonstrated the competency in problem-solving completely. The subject of the local visual level (LV) demonstrated the competency in understanding algebra and geometry as alternative languages, extracting specific information from diagrams, understanding mathematical transformations visually completely. However, the subject has not demonstrated the competency in representing and interpreting problem (or concept) graphically, and drawing and using diagrams as an aid in problem-solving completely. The last, the new level of visual thinking, the semi-local visual level (SLV) subject did not satisfied with the criteria of both existing visual thinking level. The subject has not demonstrated the competency in understanding algebra and geometry as alternative languages and extracting specific information from diagrams completely. Moreover, the subject has not also demonstrated the competency to represent and interpret problems (or concept) graphically, draw and use diagrams as an aid in problem-solving, and understand mathematical transformations visually.

\section{Conclusion}

There was the characteristic (level) of subjects that differed from those that have already existed. At a new level, it was the semi-local visual, the students could only understand algebraically. They could not extract specific information from the diagram, 
represent and interpret problems graphically, and draw/use the diagram as an aid in problem-solving. At the local visual level, the subjects understood geometry as an alternative language. They could graphically represent problems or concepts although it was incomplete. Moreover, at a global visual level, students could meet visual thinking indicators, and both understood algebra and geometry as alternative languages for problem-solving completely. They could extract specific information from diagrams and draw and use them to solve problems perfectly. The present research result suggests the changes in learning models to provide materials or problems by considering various representations. Hence, the development of the learning models or methods to improve the students' visual thinking of each level is a challenge for the researchers.

\section{Acknowledgment}

The researcher would like to thank the students of the Department of Mathematics Education at the State Islamic Institute of Tulungagung for processing the data.

\section{Bibliography}

Arcavi Abraham. (2003). The Role of Visual Representations in the Learning of Mathematics. Educational Studies in Mathematics. Educational Studies in Mathematics, 52, 215-242.https://doi.org/10.1023/A:1024312321077

Dubinsky, E. (2013). Using a Theory of Learning in College Mathematics Courses. MSOR Connections, 1(2), 10-15. https://doi.org/10.11120/msor.2001.01020010

Goldin, G., \& Shteingold, N. (2001). Systems of representations and the development of mathematical concepts. In A. A. Cuoco, \& F. R. Curcio (Eds.), The roles of representation in school mathematics: 2001 yearbook of the national council of teachers of mathematics (pp. 1-23). Reston, VA: NCTM.

Guler, G., \& Ciltas, A. (2011). The visual representation usage level of mathematics teachers and students in solving verbal problems. International Journal of Humanities and Social Science, 1(11), 145-154. Retrieved from http://www.ijhssnet.com/journals/Vol 1 No 11 Special Issue August 2011/17.pdf

Güven, B., \& Kosa, T. (2008). The Effect Of Dynamic Geometry Software On Student Mathematics Teachers' Spatial Visualization Skills The Turkish Online Journal of Educational Technology, 7(4), 100-107. Retrieved from https://files.eric.ed.gov/fulltext/EJ1102930.pdf

Hartono. (2010). Mental Imagery: tinjauan dari segi filsafat, Ilmu-ilmu Kognitif dan Neurologis. Surabaya: UNESA University Press.

Huang, C. (2013). Engineering students' visual thinking of the concept of definite integral. Global Journal of Engineering Education, 15(2), 111-117. Retrieved from http://www.wiete.com.au/journals/GJEE/Publish/vol15no2/06-Huang-C-H.pdf

Kang, R \& Liu, D. (2018). The Importance of Multiple Representations of Mathematical Problems: Evidence from Chinese Preservice Elementary Teachers' Analysis of a Learning Goal. International Journal of Science and Mathematics Education, 16, 125-143. Retrieved from https://eric.ed.gov/?id=EJ1165850

Kurniawati, N. K. (2013). Komunikasi Antarpribadi. Yogyakarta: Graha Ilmu.

Mahir, N. (2009). Conceptual and procedural performance of undergraduate students in integration. International Journal of Mathematical Education in Science and Technology, 40(2), 201 -211. https://doi.org/10.1080/00207390802213591

Nufus, H., Duskri, M., \& Bahrun, B. (2018). Mathematical Creative Thinking and Student Self-Confidence in the Challenge-Based Learning Approach. JRAMathEdu Uournal of 
Research and Advances in Mathematics Education), 3(2), 57-68. https://doi.org/10.23917/jramathedu.v3i2.6367

Presmeg, N. (2006). Research on Visualization in Learning and Teaching Mathematics. In A. Gutiérrez, \& P. Boero (Eds.), Handbook of Research on the Psychology of Mathematics Education: Past, Present and Future (pp. 205-236). Rotterdam: Sense. Retrieved form https://www.scirp.org/(S(vtj3fa45qm1ean45vvffcz55))/reference/ReferencesPaper S.aspx?ReferenceID=1503352

Roam. (2011). The magic of Picture. Translated from The Back Of Napkin. Jakarta Selatan: ufuk Press, PT. Ufuk Publishing House.

Schunk, D. H. (2012). Learning Theories an Educational Perspektive. United States of America: Pearson Education Inc.

Serhan, D. (2016). Students' Understanding of the Definite Integral Concept. International Journal of Research in Education and Science, 1(1), 84-88. Retrieved from https://files.eric.ed.gov/fulltext/EJ1105099.pdf

Sholihah, U., \& Asyhar, B. (2018). The Student's Visual Thinking Profile in Solving Mathematics Problems, (June). Proceedings of the University of Muhammadiyah Malang's 1st International Conference of Mathematics Education (INCOMED 2017) https://doi.org/10.2991/incomed-17.2018.16

Skemp, R. R. (2013). Relational Understanding and Instrumental Understanding. Retrieved from http://www.davidtall.com/skemp/pdfs/instrumental-relational.pdf

Sternberg R J. (2008). Psikologi Kognitif. Yogyakarta: Pustaka Pelajar.

Stokes, S. (2001). Visual Literacy in Teaching and Learning: A Literature Perspective. Electronic Journal for the Integration of Technology in Education, 1(1), 10-19. Retrieved from https://wcpss.pbworks.com/f/Visual+Literacy.pdf

Stylianou A, D. (2004). The role of visual representations in advanced mathematical problem solving: An examination of expert-novice similarities and differences. Mathematical Thinking and Learning, 6(4), 353-387. https://doi.org/10.1207/s15327833mt10604 1

Suh, J. M., Chris. J. \& Mills, M. (2008). Promoting Decimal Number Sense and Representational Fluency. Mathematics Teaching in the Middle School, 14(1), 44-50. Retrieved from https://eric.ed.gov/?id=E]805046

Suharnan. (2005). Psikologi Kognitif. Surabaya: Srikandi.

Tasman, F., Hertog, J. D, Zulkardi, Z., \& Hartono, Y. (2016). Helping Students Acquainted with Multiplication in Rectangular Model. Journal on Mathematics Education, 2(2), 185-198. https://doi.org/10.22342/jme.2.2.747.185-198

Umami, I. (2018). Moderating Influence of Curriculum, Pedagogy, and Assessment Practices on Learning Outcomes in Indonesian Secondary Education. Journal of Social Studies Education Research, 9(1), 60-75. Retrieved from https://jsser.org/index.php/isser/article/view/243

Van de Walle, J, A. (2008). Elementary and Middle School Mathematies. PT Gelora Aksara Pratama: Erlangga. 